\section{Uma dívida que o tempo não esmorece}

Iná Camargo Costa

Professora da Universidade de São Paulo

Joāo Roberto Faria, Vilma Arêas e Flávio Aguiar (orgs.), Décio de Almeido Prado, um homem de teatro, São Paulo, Edusp, 1997.

El barrio le respeta y, entre la barra, lo que el diga se puede dar por sentado, bailarin y buen mozo, sabe de farras... Flores, "Por seguidora y por fiel"

Para quem já sabia ser Décio de Almeida Prado o nome próprio da moderna crítica teatral no Brasil, o livro de homenagem a seus oitenta anos, organizado por Vilma Arêas, Flávio Aguiar e Joāo Roberto Faria, é o melhor dos argumentos. Agora podemos dar o conceito por demonstrado, assim como algumas de suas conseqūências mais decisivas.

Dividido em três partes, a primeira contém depoimentos que detalham a figura humana e o militante do teatro em todas as frentes - produçāo, pesquisa, crítica, ensino e formação de pesquisadores -, a segunda apresenta estudos sobre aspectos fundamentais de sua obra de crítico e historiador e, na terceira, encontram-se homenagens que estabelecem um produtivo diálogo com sua obra. Se fosse um simples registro da efeméride, a estatura do homenageado já daria motivo suficiente para nuidosas comemoraçōes, mas o livro vai muito além.

Como fica impossível tratar com justiça a massa de informaçōes trazidas pelos depoimentos, da qual emergem entre muitas a figura de um trabalhador incansável e excepcional (por um período de cerca de dez anos foi, ao mesmo tempo, professor em colégio, professor na EAD, crítico teatral e editor do Suplemento Literário do jornal $O$ Estado de $S$. Paulo!!!) e a confirmaçāo por atores, diretores e críticos, de seu papel decisivo em momento cruciais da história do teatro moderno entr nós, vamos limitar estas consideraçōes a dois aspectos: sua contribuiçāo para a crítica e a história do teatro no Brasil e os diálogos com os companheiros de geração. Mas para nāo deixar em branco esta primeira parte, vale a pena registrar que ficamos sabendo, entre outras informações valiosas, que Cacilda Becker uma vez declarou ter descoberto graças a Décio de Almeida Prado o encanto da sua arte; que ele recomendou, a um Gianni Ratto interessado em encenar uma peça brasileira, a leitura de A moratória de Jorge Andrade e, um José Renato quebrando a cabeça em busca de uma forma barata de produzir teatro, a leitura do livro de Margo Jones, Theatre in the round. Sāo depoimentos dos privilegiados que travaram contato com o crítico teatral, o professor da EAD ou o colega da Faculdade de Filosofia. E através destes últimos ficamos sa bendo também que nos tempos de estudante sua dedicação ao teatro nāo conhecia limites: foi ator, diretor, contra-regra, sonoplasta e fazia o que mais fosse preciso para garantir a realização de um espetáculo.

Ao mesmo tempo que punha a mão na massa, não descuidava de seus compromissos de estudante. Com isso, preparou - e, pelo visto, sem planos previamente traçados - seu caminho para se tornar, quase que naturalmente, nosso maior crítico teatral. Não hã segredo nisso: sua dedicaçāo ao teatro, desde o início, sempre juntou a prática e a gramática (e pensar que nāo cursou Letras por embirrar com gramática!). Com um detalhe nada desprezivel: do lado da gramática, também não se restringiu à teoria e história teatral. Bárbara Heliodora fala da solidez de sua cultura, Joāo Bethencourt, em sua enorme capacidade intelectual, Cleonice Berardinelli, em sua fina educação e Antunes Filho destaca-o como "exemplo do intelectual e de integridade moral". Todos sugerem que, com Décio, pela primeira vez no Brasil, se deu o sempre tảo necessário encontro entre exigência intelectual máxima e profundo envolvimento prático com a atividade teatral.

Os estudos sobre a obra do crítico e historiador do teatro brasileiro demonstram essa proposiçāo. Com base neles e apoio literal no que escreveu o outro mestre, Sábato Magaldi, podemos enunciar este axioma: "qualquer estudo novo sobre o teatro brasileiro tem de partir, obrigatoriamente, de seus comentários" (p. 88). Os ensaios de Joāo Roberto Faria e Antonio Arnoni Prado trazem proposiçōes importantíssimas para esses novos estudos.

Enquanto Amoni mostra a necessidade de compreender suas teses sobre os vínculos profundos entre a geração do TBC e o modernismo e, a partir delas, os seus estudos sobre a história do teatro brasileiro, a começar dos problemas do padre Anchieta em seus esforços teatrais para cristianizar nossos índios, Joāo Roberto Faria aborda o tema da formaçāo, entendido como um dos mais importantes eixos de seu trabalho crítico, deixando claro que este só poderá ser bem compreendido se conseguirmos atinar com as teses do mestre a respeito da formação do teatro brasileiro. Em outras e sumánias palavras: para além do implícito acerto de contas entre Décio de Almeida Prado e Machado de Assis, seria preciso avaliar, com mais empenho do que até agora, seu diálogo, também implícito, com os companheiros da "geraçāo clima", em especial Dona Gilda, Antonio Candido e Paulo Emilio. Trata-se de dificuldade respeitável, mas de seu enfrentamento dependem os passos que as novas geraçōes pretendam dar. Numa perspectiva sociológica, Heloísa Pontes apresenta alguns materiais a esse respeito.

Ainda neste capítulo, e para ampliar o quadro das referências, o ensaio de Eudinyr Fraga avisa que não podemos nos esquecer do papel do cinema na formaçāo da sensibilidade artística daqueles jovens. E como Alberto Guzik destaca duas obras máximas de Décio de Almeida Prado, Apresentaçāo do teatro brasileiro moderno e Teatro em progresso, essenciais para a reflexāo sobre o tópico, mencionando que elas já se tornaram raridades bibliográficas, seria o caso de se perguntar a Jacó 
Guinzburg - que promete para breve um trabalho ampliando o ensaio em co-autoria com Nanci Fernandes aqui publicado - quais as chances destes dois livros passarem a compor finalmente, numa mesma coleção, a neces sária trilogia de críticas sobre o teatro brasileiro moderno, ao lado de Exercício findo. Sem querer abusar das encomendas, registre-se que Eudinyr Fraga também menciona críticas que não foram publicadas em livro: eis aí mais un trabalho editorial tornado obrigatório por esta boa lembrança. Sem dúvida, tal publicação haverá de fazer diferença.

Flávio Aguiar e Ana Bernstein enfrentam de modo mais detido os problemas relativos à arte do ator, não por acaso considerados relevantes por quase todos os ensaístas que colaboram neste livro; afinal, de Joāo Caetano a Cacilda Becker, e por razōes que Flávio explicita desde a epígrafe, atores sempre receberam uma atençāo muito especial por parte de nosso crítico. Ana Bernstein, numa exposiçāo muito convincente, aproxima o pensamento de Décio de Almeida Prado ao de Stanislavski e, se ela tiver razāo, teremos dado um passo importantíssimo na definiçāo de pelo menos um dos alicerces de sua teoria teatral. O mesmo vale para Flávio Aguiar, que pelo ângulo do trabalho do ator tratou de expor as bases sobre as quais o crítico, ao mesmo tempo que elabora uma complexa reflexāo sobre a história do teatro no Brasil, apóia a defesa da autonomia da arte.

A parte final, dos estudos dedicados ao mestre, foi dividida em dois blocos. No primeiro, seus amigos e companheiros de universidade com ele dialogam a partir de suas próprias pesquisas, e o segundo contém outros ensaios sobre teatro. Esta segunda parte abre com um estudo sobre o Joāo do Rio dramaturgo, de Marta Morais da Costa, que constitui uma amostra de como o mestre Décio ensinou a ler peças teatrais e suas conclusōes interessam para quem quer pensar também em nossos múltiplos episódios de modernizaçāo. Antonio Dimas faz um pequeno e precioso desvio de suas pesquisas sobre Olavo Bilac, apresentando e comentando alguma das crônicas do poeta ao mesmo tempo preo- cupado em civilizar o país e expor a importância que poderia ter o teatro nesse mesmo processo, papel que, a seus olhos, por alguma razāo muito arraigada, os profissionais do ramo se recusavam a assumir. Dimas não deixa dúvidas: para Bilac, o mais grave na situação do teatro do início deste século seria a falta de profissionalismo, a improvisaçāo e o desrespeito ao público. Se considerarmos que essa falta de respeito incluía apresentaçōes em espaços como um certo "galpāo hediondo, velho, sujo, incômodo" (p. 395), fica difícil evitar o pensamento de que alguma coisa daquele quadro ainda persiste até hoje. E, por contraste, este cenário permite também entender melhor a luta da geraçāo de Décio de Almeida Prado.

Mestre Jacó Guinzburg ergue um segundo brinde ao amigo com um estudo sobre a trajetória de Meyerhold. Além de mostrar como o diretor russo corneça procurando inventar uma cena para o drama simbolista e chega à biomecânica, passando pela Revolução de Outubro, o professor Guinzburg estabelece os elos, agora indiscutiveis, entre este resultado e as propostas mais tarde desenvolvidas por Brecht na Alemanha. E, agora que não existe mais a sombra da União Soviética para atrapalhar, passa a ser possível examinar com materiais confiáveis, como já se pode ver neste ensaio, o registro implacável do brutal retrocesso social promovido pelo stalinismo que Meyerhold fez na encenaçāo de $O$ inspetor geral, por exemplo.

Marlyse Meyer fecha o bloco com as lembranças provocadas pela leitura do ensaio de Décio de Almeida Prado sobre o teatro romântico. Como em tudo o que escreve, aqui ela nos apresenta um conjunto de experiências, como as do maio de 1968 francês, cujo caráter pessoal não a impede de iluminar momentos decisivos de nossa história recente. A essas experiências (enfrentamento com a repressāo, espetáculos teatrais, debates teóricos etc.) mesclam-se análises e reflexōes que não podem mesmo ser separadas de seu contexto. Nảo satisfeita, apresenta-nos um roteiro completo das leituras que precisamos fazer a partir de uma peça como o Lorenzaccio de Alfred de Musset (nāo por acaso também, sobre um tópico político de extrema atualidade).
Os estudos que não dizem respeito diretamente a teatro, na medida em que sāo dedicados a mestre Décio, formam uma espécie de painel de referências com as quais temos que nos haver se quisermos mesmo acatar a recomendaçāo de Sábato Magaldi. Assim, o ensaio de Alfredo Bosi sobre as tribulaçōes do padr Vieira é importante contraponto aos dois primeiros capítulos do livro Teatro de Anchieta a Alencar. O de Aderaldo Castello, sobre narra dores e poetas nordestinos, pōe nosso crítico entre dois gêneros literários de que nāo tratou exclusivamente pela divisăo de trabalho estabelecida na revista Clima. Uma das prova cabais de que ele poderia ter se dedicado com igual competência a qualquer um deles, para além do trabalho de editor do Suplemento Lite ránio, é seu breve ensaio sobre Carlos Gardel no livro Seres, coisas, lugares. Carlos Augusto Calil, ao revelar nas relaçōes entre os paulistas e Blaise Cendrars a matriz francesa das preocupaçōes dos nossos primeiros modernistas com o patrimônio histónico, acrescenta mais um elo à cadeia de relaçōes culturais mais profundas entre Brasil e França.

Chamando a nossa atençāo para a periferia do trabalho crítico, Antonio Candido, como sempre, nos diz muito mais do que somo capazes de perceber à primeira vista em seu relato sobre os caminhos (e aventuras) de sua descoberta de François Villon. A primeira notícia, mal e mal registrada, veio ainda na infância através do cinema, num filme em que John Banrymore interpretou o personagem. Muitos filmes depois, o interesse por artes plásticas e a leitura de entrevistas de Rodin levam-no a topar com os versos do poeta. Mais tarde, já estudante em Sāo Paulo, encontra uma edição francesa dos poemas que até hoje, inúmeras ediçōes e estudos depois, incendeiam a sua imaginação. Isto fica demonstra do nos comentários analíticos que, dando destaque a imagens e construçōes poéticas voltadas para a morte, a decadência $e$ os efeitos da passagem do tempo, nāo deixam de conter uma mensagem (política) otimista, na medida em que são príncipes, nobres, religiosos e cortesās os objetos preferenciais daquelas determinaçōes. Não será difícil extrair desse ensaio conclusões que ajudem a compreender o trabalho do seu amigo Décio, que também passou com igual empenho pelo cinema, artes plásticas, poesia, ópera e demais interesses culturais daquela geraçāo.

O título desta resenha foi tomado de em préstimo ao depoimento de Gianni Ratto. Mas o livro pede uma correçāo: em lugar de esmorecer, o tempo aumenta a nossa dívida para com o mestre Décio de Almeida Prado. O próprio livro lhe acrescenta um novo item. Como se isso nāo bastasse, desconfio que, se nāo fosse por esta homenagem, tāo cedo nāo tomaríamos conhecimento da traduçăo em que há tempos Dona Gilda vinha trabalhando. Trata-se de um dos grandes poemas de T. S. Eliot, "The love song of J. Alfred Prufrock". Como não tem cabimento proceder aqui a uma análise dessa tradução, muito menos a um comentário do poema, contentemo-nos a título de despedida com reproduzir parte da estrofe que, tomando o tema do terceiro capítulo do Eclesiastes como ponto de partida e passando por Hesiodo, mergulha-o em elementos inescapáveis da experiência moderna:

Ainda há tempo, ainda há tempo

De compor um rosto que irá encontrar os rostos dos encontros, Ainda há tempo de matar e de criar, E tempo para todos os trabalhos e dias de mãos Que erguem e deixam cair uma questāo em nosso prato.

Tempo para você e tempo para mim

E tempo para urna centena de indecisões

E para uma centena de revisōes.

Antes de se tomar chá com torradas. 